\title{
Televisão, narrativa e restos do passado $^{1}$
}

\author{
Marialva Barbosa ${ }^{2}$ \\ Universidade Federal Fluminense
}

\begin{abstract}
Resumo: $O$ artigo procura mostrar que existe um modo próprio de contar história da televisão, que permite afirmar a existência de uma narrativa televisual. Determinados aspectos da linguagem formam constantes em termos de peculiaridades e particularidades, que não se confundem com emissões de outros meios audiovisuais. Essas constantes são as articulações temáticas, a dependência da forma dos regimes de oralidade e modos de comunicação que instauram "modos de ver" particulares. São essas características dos modos de contar da televisão - não importa se em gêneros dependentes da convenção de veracidade ou de ficcionalidade - que estamos particularizando como narrativa televisual. Num segundo momento, mostraremos como a televisão articula sua narrativa temporalmente, colocando passado, presente e futuro em regimes de compreensão próprios. $O$ presente dilatado, o passado como resto e o futuro como espera reproduzem a lógica do tempo vulgar na tela da TV e modos de contar cotidiano. Poderíamos, então, dizer que a narrativa televisual se insere nesse desejo de moldar novas vistas esquemáticas sob a forma de contar histórias? Até que ponto a televisão constrói novas formas narrativas? $E$ como essas construções estabelecem a conexão com o passado, através do que chamamos vestígios memoráveis, e com o futuro, através do sentido de espera? Enfim, como os vestígios memoráveis informam sobre a narrativa televisual e sua relação com o tempo? São essas perguntas fundamentais que direcionam o sentido desse texto, que é resultado da pesquisa Mídia e Cerimônias Festivas da TV Brasileira, financiada pela FAPERJ (Cientista do Nosso Estado) e pelo CNPQ (Bolsa Produtividade e Pesquisa).
\end{abstract}

Palavras-Chave: Narrativa - Tempo - Televisão.

1 Este artigo é uma síntese do capítulo 1 do livro Televisão: Temp(l)o de cerimônias, ainda inédito.

2 Doutora em História e Professora Titular do Programa de Pós-Graduação em Comunicação da Universidade Federal Fluminense e do Departamento de Estudos Culturais e Mídia da mesma universidade. 


\begin{abstract}
The purpose of this article is to demonstrate the existence of a particular way of telling the history of TV which allows us to say that there is a television narrative. Certain aspects of its language assume the form of constants in terms of peculiarities and particularities, that cannot be mistaken for those of other broadcasting systems. These constants are: thematic articulations, the dependence on orality regimes, and modes of communication that establish particular "modes of seeing". These are the characteristics of the mode of telling on TV - no matter whether in genres dependent on the conventions of veracity or fictionality - that we are particularizing as television narrative. Secondly, we will demonstrate how television articulates its narrative in time, putting past, present and future in distinct comprehension regimes. An expanded present, a past in the form of vestige and a future as expectation reproduce both the logic of vulgar time on the small screen as well as modes of telling in everyday life. Could we then say that television narrative can be inserted in this longing to mould new scheme views under the form of storytelling? To which extent does television build new narrative forms? How do these constructions establish a connection with the past, through what we call memorable vestiges, and with the future as well, through the sense of expectation? Finally, how do memorable vestiges inform about television narrative and its relation to time? These are the fundamental questions that guide this work, which is itself the result of a research called/Media and Festive Ceremonies on Brazilian Television/, sponsored by FAPERJ ("Scientist of Our State" Project) as well as by CNPQ ("Productivity and Research" Scholarship).
\end{abstract}

Resumen: El artículo busca demostrar que una manera apropiada existe para contar la historia de la televisión, eso permite para afirmar la existencia de una narrativa televisual. Los aspectos resueltos de la lengua forman constantes en términos de particularidades de que no se confunden con las emisiones de otros medios. Estas constantes son los empalmes temáticos, la dependencia de la forma de regímenes del oralidad y las maneras de la comunicación que restauran "maneras de considerar". Son estas características de las maneras a la cuenta de la televisión - no importa si en las clases dependientes de la convención del ficción o de la veracidad que estemos distinguiendo como narrativa televisual. Después, demostraremos como la televisión articula su narrativa secular, poniendo pasado apropiado, el regalo y el futuro en regímenes de entender. El presente dilatado, el pasado como porción restante y el futuro como espera reproducen la lógica del tiempo vulgar en la pantalla de la TV y de las maneras de contar diariamente. ¿Podríamos, después, decir que la narrativa televisual si los rellenos en este deseo de moldear nuevas vistas esquemáticas bajo forma para contar historias? ¿Hasta punto la televisión construye a las nuevas formas narrativas? ¿E como estas construcciones establecen la conexión con el pretérito, con qué nosotros llama vestigios memorables, y con el futuro, con la dirección de la espera? ¿En el último, como los vestigios memorables informe en la narrativa televisual y su relación con el tiempo? Son estas preguntas básicas que dirigen la dirección de este texto, de que se resultan de los medios de la investigación y de las ceremonias festivas de la TV brasileña, financiados para el FAPERJ (científico de nuestro estado) y para el CNPQ (productividad e investigación).

Résumé : L'article cherche à montrer qui existe une manière propre de raconter l'histoire de la télévision, qui permet d'affirmer l'existence d'un récit propre de ce medium. De certains aspects de la langue forment des constantes dans des termes de particularités et des peculiarités, qui ne se confondent pas 
avec des émissions d'autres moyens audiovisuels. Ces constantes sont les joints thématiques, la dépendance de la forme des régimes d'oralité et les manières de communication qui instaurent des "manières de voir ». Ce sont ces caractéristiques des manières de compter de la télévision - il n'importe pas si dans des types dépendants de la convention de véracité, ou bien, de ficcionalidade - que nous distinguons son récit. Après, nous montrerons comme la télévision articule son récit, en plaçant du passé, du présent et de l'avenir dans des régimes de compréhension propres. Présent dilaté, le passé comme reste et l'avenir comme attente reproduisent la logique du temps vulgaire dans l'écran du TV et les manières de compter quotidien. Nous pourrions, alors, dire que ce récit s'insère dans ce désir de mouler de nouvelles vues schématiques sous la forme de raconter des histoires ? Jusqu'à ce que point la télévision construit de nouvelles formes narratives? Et comme ces constructions établissent la connexion avec le passé, à travers lesquelles nous appelons vestiges mémorables, et avec l'avenir, à travers le sens d'attente? Enfin, comme les vestiges mémorables informent sur le récit et leur relation avec le temps? Ce sont ces questions fondamentales qui dirigent le sens de ce texte, qui est en résultant de la recherche Mídia et Cérémonies : de fête du TV Brésilien, financée par FAPERJ (Scientifique de Notre État) et par CNPQ (Bourse Productivité et Recherche).

Ao dizer que a televisão instaura modos próprios de contar história que nos permite afirmar a existência de uma narrativa particular - a televisual -, não estamos negando a existência da categoria gênero, mas considerando como determinante a particularidade dos atos de contar história que está no cerne da produção discursiva do meio.

Portanto, não desconhecemos que há na televisão diversos gêneros, mas por uma questão teórica privilegiamos os modos de ver, as formas comunicacionais e $\underline{o}$ gesto do telespectador que, no nosso entendimento, constroem as particularidades dessa narrativa. 
A linguagem da televisão pode ser considerada como obra de síntese (RICOEUR, 1994). Tendo como síntese o som e a imagem, mas também as performances de uma oralidade secundária, se utilizamos a categoria de Walter Ong (1998), a narrativa da TV particulariza objetivos, causas e acasos reunidos numa unidade temporal de uma ação total e completa (RICOEUR, op. cit., p. 9-20). Mas qualquer narrativa coloca em cena a intriga, o novo, o inédito, o não-dito, as peripécias, os acasos, articulando a ação humana no tempo.

Assim, se qualquer narrativa é obra de síntese e coloca em evidência a intriga numa rede temporal, o que particulariza as emissões da televisão?

No nosso entendimento, não é a estruturação da programação na lógica de fluxo, como mostrou Williams (1990), que permite a sua particularização. A rigor, são as articulações textuais em intrigas e a colocação em cena de peripécias sempre renovadas, ao lado de performances da oralidade, que permite caracterizar as peculiaridades dessa narrativa.

O ritmo e a composição das cenas televisivas são governados pela idéia de fluxo: um contínuo de imagens que não faz distinção dos programas constitui, para Williams (op. cit.), a forma televisão. Para Barbero (2001), o fluxo televisivo produz a metáfora mais real da substituição dos grandes relatos pela equivalência de todos os discursos (informação, drama, publicidade, dados financeiros, etc), pela inter-penetrabilidade de todos os gêneros e pela transformação do efêmero em chave de produção e em proposta do gozo estético da TV. O fluxo televisual é, para ele, mediação estratégica que remete a novos modos de estar junto, a novas sociabilidades cotidianas no caos urbano, introduzindo outra espécie de continuidade: a das redes e dos circuitos, enfim, a dos conectados (p. 36-37).

É a lógica de fluxo que faz também com que todos os sentidos humanos sejam como que aprisionados pela televisão. Como mostrou Derrick de Kerckhov (1997) - a partir de um experimento realizado diante de emissões, no qual procurava exprimir o que gostava ou não em imagens sucessivas que mudavam a cada 15 segundos, experiência gravada e que indicou que todas as alterações foram percebidas no corpo do pesquisador submetido ao experimento -, a televisão fala, em primeiro lugar, ao corpo e não à mente. Na sua avaliação, a tela do vídeo impacta 
diretamente o sistema nervoso e as emoções dos telespectadores. Portanto, para Kerckhov o regime de processamento da informação da televisão se realiza na tela.

A segunda conclusão do autor, a partir de seu experimento, é que a televisão é hipnoticamente envolvente. Qualquer alteração na tela atrai à atenção. Essa fixação não permite a volta do pensamento, a reflexão. A imagem fica numa espécie de zona de sombra encoberta do consciente.

Portanto, cognitivamente a televisão foi construindo uma linguagem que desobriga, no momento da emissão, a reflexão e a transformação mimética da narrativa. Isso se dará quando a tela se apagar, abrindo a possibilidade de reconstrução permanente. A gramática fragmentada do meio relaciona-se com a forma como a tecnologia atua no público. E o contínuo temporal instaurado por sua narrativa está na dependência direta das possibilidades oferecidas pela tecnologia.

A lógica da narrativa da televisão diz respeito primeiramente às articulações temáticas: coloca em evidência o cotidiano das maiorias, apelando às sensações do público. Do extraordinário coletivo à vida comum de existência a mais privada, tudo é re-configurado como excepcional e, ao mesmo tempo, cotidiano. A primeira proximidade se realiza, portanto, por regimes de identificação.

A linguagem da televisão apela a valores, sentimentos e emoções corriqueiras. É o comum que figura na cena. São personagens saídos de um pretenso "real" e configurados pelo olhar de quem vive a existência que a TV veicula em situações sempre performáticas.

Portanto, não existe um espaço demarcado exclusivamente para o ficcional e outro para a informação: o ficcional se embaralha com emissões que são dependentes das convenções de reprodução do real. É também essa mistura que faz com que a fala da televisão seja antes de tudo uma narrativa.

No que diz respeito especificamente à forma há que se considerar a dependência dos regimes de oralidade. Na cena da TV há sempre - seja nos telejornais, seja nas telenovelas, seja nas séries, nos programas de auditório e também nas emissões que durante horas interrompem a programação habitual - a reprodução, nos mínimos detalhes, das maneiras como o público estabelece suas falas no cotidiano. As palavras são construídas num contexto de locução, no qual a 
imagem de quem fala, a sua entonação e seu gestual são fundamentais para a compreensão do dito e do não-dito. As emissões reproduzem os diálogos em gestos corporais múltiplos: a discussão de diversos personagens, a troca de idéias, valores, informações entre dois personagens, o diálogo solitário dos que exprimem a voz como pensamento. Há ainda o diálogo mais emblemático: o da cena da TV com o público.

Para Paul Zumthor (1993) o fundamental na definição da situação de performance é exatamente a coincidência no tempo entre a comunicação e a recepção, ou seja, o fato de a transmissão se dar sempre em presença. A televisão pressupõe invariavelmente essa coincidência na sua criação de seus atos de público. E é este último diálogo, sempre presente nas emissões da TV, que marca definitivamente o lugar da oralidade e da narrativa nas estratégias da forma televisão.

Durante as emissões, as imitações das conversas estão sempre em destaque. As emissões, por outro lado, são destinadas a um público imaginado, de tal maneira que podemos dizer que gênero resume-se à forma presumida pelo público.

A percepção dominante passa a ser visual, mas a memória acionada é sempre acústica. A imagem existe na dependência dos atos de vocalidade (ZUMTHOR, op.cit.), ou seja, na dependência da voz. É a voz funcionando em conjunto com as imagens que ativa os diversos lugares de possibilidade de diálogo da televisão com o público. A narrativa televisual, portanto, acopla num único corpo voz e imagem, reproduzindo no aparelho tecnológico as cenas que se dão em presença, sob a forma de ausência. Ou seja, são as cenas cotidianas, as imagens já vistas e as situações já vividas que voltam sob a forma de representação, colocando em evidência uma espécie de memória da experiência do público. A narrativa da TV usa o repertório limitado do olho, produzindo padronizações. São essas padronizações que dominam as emissões. Daí a repetição de fórmulas, de situações, de imagens, de diálogos e de gestos.

A voz concreta completa a imagem que existe na e pela voz. A gesticulação visual das práticas da oralidade se transporta inteira para a narrativa. Criam-se laços de afetação com o público no qual este desempenha múltiplos papéis: a narrativa televisual reproduz, enfim, as ações humanas. 
Ainda no que diz respeito à forma, esta narrativa mistura a linguagem tratada acusticamente, segundo princípios da ressonância, com a representação imagética cujos princípios dominantes são arquitetônicos. Sua forma é, portanto, um duplo, onde estão figuradas as imagens vividas no cotidiano e a maneira como são experimentadas.

Para assistir aos jogos do campeonato mundial de futebol, por exemplo, é preciso se vestir especialmente para a festa comunhão. A camisa da seleção brasileira, a corneta que emite grunhidos incessantes ou mesmo as unhas pintadas com as cores da bandeira, tudo compõe o ritual para se tornar público diante dessas emissões festivas. Da mesma forma nas cerimônias fúnebres transmitidas pela TV o gesto de consternação é indispensável.

A televisão se constitui na principal mediação cultural da contemporaneidade. O mundo cotidiano se torna uno a partir de temas, afetos e sensações observados na tela da TV.

No que diz respeito aos modos de comunicação, aciona maneiras de ver particulares. Partindo da idéia fundamental de que a forma possui um significado e que não é a tecnologia que determina a maneira como se materializará em usos e sim ingerências de natureza política, a televisão assumiu o caráter de utensílio privado. $\mathrm{O}$ fato de ter sido absorvida, sobretudo, no âmbito da casa foi fundamental para definir como o público se relaciona com o meio.

Há que se considerar, para refletir sobre a forma como o público se relaciona com um meio de comunicação, a questão das materialidades (CHARTIER, 1987 e 1993). Se a página do livro pressupõe o manuseio, a virada da folha, a linearidade do pensamento que caminha linha após linha do começo em direção ao fim, a televisão como objeto material induz a distintas maneiras de "ler". Por outro lado, acionam-se processos cognitivos totalmente diversos.

A televisão como objeto físico - um artefato que possui uma tela iluminada de onde emergem imagem e som - pressupõe formas de se relacionar extremamente particulares. A linha do olho deve se voltar de frente para o objeto. Assim, a TV ocupa, em função da sua própria materialidade, lugares determinados para o exercício de ver. A sua frente uma cadeira, uma cama, um lugar para sentar, deitar e 
ver televisão. O seu deslocamento da sala para outros lugares da casa, também em função de novas materialidades, faz supor a multiplicação do espaço visual e sonoro e a inclusão de novas práticas comunicacionais do público.

Se inicialmente a televisão ocupava espaço nobre na sala de visita, com a tela escondida por um móvel ornamento que muitas vezes acoplava também o aparelho de som, rapidamente se autonomizou de outros aparelhos tecnológicos e deixou visível a tela como possibilidade aberta para a experiência ao simples acionar de um botão.

Abrindo a porta da sala, o telespectador entrava no universo privado da casa e podia - ao acionar um botão - voltar novamente para o espaço público, via emissão da TV.

Sua eclosão no espaço doméstico estava, pois, na simples dependência de um gesto individual. Não era preciso sair de casa para estar em contato com outras realidades e outros mundos. Mundos inclusive imaginários. Ao contrário de outras narrativas audiovisuais, como o cinema, a televisão pressupõe entrar no espaço privado para se tornar pública. A privatização, como enfatiza Williams (1979), traz como conseqüência a necessidade imperativa de contato, ainda que na dimensão da ausência-presença estabelecida por este artefato tecnológico.

De lugar entronizado na sala, à medida que a tecnologia se populariza também se multiplicam os ambientes da televisão dentro da casa. A diminuição no formato permitiu sua migração para espaços cada vez mais íntimos e a possibilidade de se postar isoladamente diante de sua tela. As condições de acesso, no sentido amplo, inclusive econômico, levaram a multiplicação dos aparelhos pelos cômodos, o que significou modos de ver diferenciados. Podia-se sozinho ver televisão, podia-se ver televisão enquanto se cozinhava, podia-se ver televisão sem olhar a tela da TV, entre diversas outras possibilidades

Os modos de comunicação instaurados diante do artefato televisão pressupõem hábitos, práticas, relações e suas significações dependem dessas cadeias cotidianas. O hábito de ver televisão se faz por ações introduzidas no dia-a-dia de milhões de pessoas. O contato com o meio significa alterações nos modos de vida. 
O advento do controle remoto incluiu novos gestos. Ao invés de acionar um botão conectado no aparelho, tem-se uma prótese estranha a ele, mas que permite a realização de múltiplas funções. Trocar de canais tornou-se uma operação tão simples que o ato de zapear passou a ser corriqueiro. Troca-se de canais diante da possibilidade de estar em contato com uma emissão mais interessante ou para poder ver ao mesmo tempo outra transmissão (ainda que o que figure em cena seja a sensação de imagens entrecortadas). E com isso cada telespectador constrói a especificidade de seu programa. A emissão passa a ser diferente para cada um: no lugar de uma sucessão linear, tem-se a expansão da idéia de fluxo para além da programação específica de um canal.

As tecnologias de cristal líquido e digital mudando mais uma vez a materialidade do meio trouxeram conseqüências também sobre os modos de ver. A televisão cuja dominância se fazia no espaço privado da casa (ainda que nunca tenha sido sua exclusividade, uma vez que sempre esteve em maior ou menor grau presente na rua), assume lugar cada vez mais representativo nos espaços públicos.

Se desde a sua implantação, a TV passou a fazer parte da paisagem das pequenas praças das cidades do interior, nas últimas décadas a materialidade televisão se espalhou por restaurantes, bares, shoppings, aeroportos, entre dezenas de lugares públicos. Com a diminuição da espessura do aparelho, torna-se espécie de ornamento na parede de onde saem imagens agora em alta definição. A realidade parece ser intrínseca à televisão. Só existe nela e a partir dela.

No burburinho dos lugares públicos, a televisão é apenas ornamento na paisagem e, de quando em vez, telespectadores dispersos se conectam com as imagens que fluem como num turbilhão. Caleidoscópio de cores que compõe o cenário e sons que se misturam no ar. Não se sabe mais que sonoridade vem da televisão e qual faz parte do ambiente urbano.

Nas datas que possibilitam a criação de cerimônias festivas que são transmitidas pela televisão num tempo contínuo, como por exemplo eventos esportivos, como a Copa do Mundo, passa a fazer parte de um cenário grandioso. Espalham-se telões gigantescos pelas praças públicas, pelos estádios vazios de jogadores, em cidades longínquas de onde estão sendo realizadas as competições, 
para que se tenha a sensação de estar conectado, de estar junto, de assistir a transmissão numa espécie de comunhão.

Portanto, a tecnologia em pouco mais de cinco décadas afetou decisivamente a materialidade do meio, trazendo conseqüências sobre os modos de ver e novas experiências audiovisuais, instaurando novas relações com a realidade e outras percepções do espaço e do tempo.

As emissões da televisão possibilitaram desde sempre a construção de múltiplas espacialidades ou, como enfatiza Barbero (2001), a desterritorialização dos modos de presença, tornando a percepção do outro, antes longínquo e desconhecido, cada vez mais próximo e reconhecido. O vivido à distância torna-se fisicamente mais perto e a televisão possibilita vivenciar o distante como parte da experiência doméstica (op. cit, p. 33).

Se os modos de ver televisão, no que diz respeito ao espaço, incluem a construção da sensação de proximidade, no que se refere à categoria tempo, as lógicas narrativas são particularmente marcadas pelo culto ao presente. A sensação de simultaneidade permanente, de instantaneidade e de emissões que se sucedem num contínuo cria uma espécie de culto ao presente. Esse presente estendido é resultado não apenas dessa valorização, mas sobretudo da forma como é narrado: instaura-se invariavelmente uma linha linear de tempo, em que o passado mistura-se à lógica do agora e à expectativa futura. É como se o presente comportasse, ao mesmo tempo, o passado como experiência e o futuro como espera.

Mas a inclusão do futuro nas grades da programação não se dá apenas quando o excepcional entra em cena. Há diferentes expectativas de futuro construídas nas representações da TV, como espera, tal como particulariza Ricoeur (1994), ainda que estas sejam cristalizadas por imagens sínteses. Nas emissões há a multiplicação de caracterizações das idades da vida e das possibilidades que o futuro engendra para cada grupo. Nas telenovelas, por exemplo, os jovens caminham em direção à realização num futuro, enquanto aos velhos estão destinadas a passividade e a permanência numa vida que se repete monotonamente a cada dia. Espera-se a morte também nas emissões da TV. A vida adulta é marcada por rupturas: hiatos de tempo que reproduzem as vivências cotidianas. A infância é um eterno vir a ser. 
Também o passado é re-configurado pela experiência televisão. Sobretudo nas comemorações, o pretérito comparece em cena como instaurador do presente. Comemora-se pela TV as grandes datas nacionais, síntese de um passado que se quer memorável, elegendo-se aspectos desse pretérito que precisam ser atualizados e relegando outros à categoria de esquecido. Nos textos ficcionais, o passado pretende ser recuperado na sua integralidade. Nas cenas de época - seja nas séries, seja nas telenovelas - pela imagem, mais do que pela palavra, se pretende integralizar e restaurar o momento anterior. Móveis, utensílios, residências, vestimentas, restos do passado, que abrem uma espécie de janela para um mundo que não mais existe, são minuciosamente escolhidos e procuram restaurar uma ambiência que só existe sob a forma de sonho.

Assim, a questão do tempo é fundamental para particular as especificidades da gramática da televisão. Seu discurso é constituído por uma espécie de bricolagem dos tempos - reunido num tecido múltiplo às complexidades e ambigüidades do presente com o passado e apresentado expectativas de futuro - produzindo a compressão do presente, que passa a incluir o futuro. O tempo extensivo da história se transforma no tempo intensivo do instante (BARBERO, op. cit, p. 35).

A narrativa da televisão se constrói apelando ao sensório. Valores próprios de um imaginário governado pelo afeto, pela afetação e pelas sensações são colocados diante do público. O sensorial é o discurso dominante: um mundo que se constitui sob a forma de imagens e uma época marcada pelas imagens do mundo. A TV foi fundamental para que passássemos, tal como afirma Barbero (op.cit., p. 52), da cidade letrada, tão bem descrita por Angel Rama (1985), à cidade comunicacional.

\section{Narrativa e Tempo}

Para Ricoeur (1994), o tempo é fundamental para a construção da categoria narrativa. Através da narrativa re-atualizamos permanentemente nossa experiência solitária e muda. Mas isso só se dá se houver a re-configuração textual através da experiência temporal. Assim, falar em narrativa pressupõe se referir a uma forma que é trans-cultural e que coloca em evidência o caráter temporal da experiência humana (Idem, p. 85). 
A questão da narrativa tem sido objeto de reflexão de múltiplos autores3. Entretanto, na definição que estamos considerando narrativa, fundamental é a forma como Paul Ricoeur tece o conceito baseado inicialmente nas aporias do tempo de Santo Agostinho e nas reflexões contidas na Poética de Aristóteles.

A narrativa da televisão - seja ela de que gênero for - produz a transição entre a experiência que precede a construção do texto e a que lhe é posterior (a do público) e só ganha sentido quando passa a figurar nesse novo mundo. Introduz uma espécie de suspensão do tempo - o presente do telespectador - por um passado que agora está na tela e é apresentado como presente vivido, instaurando "o mundo das coisas contadas" (RICOUER, 1995, p. 115-116). Neste sentido, não há diferença entre narrativa ficcional ou não ficcional. Daí também o embaralhamento de significações que o público produz em relação aos gêneros televisuais, misturando ficcional e factual.

A narrativa imagética instaura um paralelismo sem precedente na temporalidade em cena pelo ato de narrar. Há a construção da coincidência entre o tempo do ato de narrar e o tempo do texto de contar. A ação se dá no instante da produção do ato elocutório, fazendo com que o narrador seja associado aos eventos, transformando-o em testemunha.

Só pode haver compreensão se o significado produzido puder ser aprisionado pelo espectador que dele fará múltiplos usos. E é, nesse sentido, que a televisão é produtora de significados e não mera operadora e coloca em circulação mensagens destinadas ao público, também ele produtor de significados. É o público que imaginando o tempo do ato (a partir do tempo contado) precipita a narrativa, condensando em eventos exemplares seus traços duradouros.

É, portanto, na interação com o público, da relação que estabelece entre o tempo da narração e o tempo da vida, através do ato de contar, que a televisão

\footnotetext{
3 Exemplos dessas abordagens são as de T. Todorov (1979), Roland Barthes (1970) e Gerard Genette (1972 e 1983). Gennete define narrativa como "a representação de um acontecimento ou uma série de acontecimentos, reais ou fictícios, por meio da linguagem, e mais particularmente da linguagem escrita" (1973, p. 255). No mesmo texto, entretanto, adverte para os perigos de se definir narrativa com tanta categorização, já que definir é "acreditar, talvez perigosamente, na idéia ou no sentimento de que a narrativa é evidente”. É necessário, segundo ele, chamar a atenção para os aspectos singulares, artificiais e problemáticos do ato narrativo.
} 
operacionaliza seus textos. É neste ato do contar que ocorre o diálogo do público com os meios, produzindo o que Barbero (1998) classifica como mediações. Mediações como "lugares dos quais provêm as construções que delimitam e configuram a materialidade social e a expressividade cultural da televisão". Nos atos cotidianos do público, portanto, as mediações podem ser vistas como atos configurantes e produtores de novos sentidos.

$\mathrm{Na}$ casa do telespectador, na sua rotina diária, irrompem imagens que colocam em cena o ficcional, com todos os jogos temporais, interpelando-o a partir desse lugar, e construindo uma tessitura que remete às exigências dos leitores e atende às necessidades de expressão nas suas experiências privadas. Neste sentido, podemos dizer que o tom coloquial, a simulação de diálogos e a construção de personagens arrancados do mundo comum não devem ser explicados apenas como simulação do que é familiar para o público, e sim como exigência dos telespectadores, que a partir do texto compõe sua própria expressividade.

Expressividade que faz das práticas da oralidade a forma mais contundente do diálogo comunicacional na televisão, como já enfatizamos. Mesmo nas narrativas que têm a pretensão de informar, o lócus de produção discursiva se dá num ambiente que reproduz cenas da oralidade. Nos telejornais, por exemplo, os locutores jornalistas apresentam-se sempre em dupla, reproduzindo um diálogo no qual o público é peça fundamental. Falam olhando diretamente para o telespectador que é imaginado na cena. Nos últimos anos, essa estratégia foi exacerbada com a construção de cenários que reproduzem salas de visita, onde os locutores principais (sempre em dupla) esperam a entrada em cena de um novo personagem: o comentarista especializado. Os personagens - jornalistas, na sala de visita do telejornal, reproduzem diálogos múltiplos, conversas, que materializam cenas cotidianas e diárias de um mundo oralizado.

Outro ponto central da narrativa da televisão é a instauração de uma temporalidade particular e de contornos em torno do tempo de contar e tempo levado para contar (RICOUER, 1995). A simultaneidade dos diálogos com a produção do próprio acontecimento, nas emissões jornalísticas, muitas vezes produz um hiato no tempo, fazendo com que se produza uma coincidência entre o ato de contar e o tempo que o narrador leva para contar. O passado torna-se presente e provoca suspensão no 
presente vivido pelo telespectador que passa a figurar na narrativa, compondo um novo presente: o presente contado da narrativa.

O improviso da cena, como recurso ao tempo presente, se por um lado produz a sensação de imediatismo, por outro permite transcrever quase que simultaneamente os sentimentos experimentados e suas circunstâncias. A retórica do improviso, construída de maneira freqüente, promove a aproximação do texto ao sentimento. Daí a permissividade para a expressão, emoção, sentimentalismos que irrompem muitas vezes também a narrativa informacional que, em princípio, precisaria de distanciamento. Mas a narrativa da televisão entremeia esse improviso com a idéia generalizada de documentação, sobretudo nos textos com pretensão à verossimilhança, considerando, portanto, a falibilidade da memória do narrador e a necessidade de recorrer ao documental como prova material da existência.

Ainda que a televisão seja dependente da idéia de fluxo (WILLIAMS, op. cit.), como já enfatizamos, o público é capaz de regular o tempo vivido pela grade de programação das emissoras. O relógio contemporâneo é o midiático, o que faz com que cotidianamente se possa produzir uma demarcação temporal a partir da lógica narrativa da televisão. Saíamos antes ou depois do Jornal Nacional, jantamos antes ou depois da novela das oito, acordamos para ver o primeiro telejornal do dia.

A programação que se repete - todos os dias haverá as novelas, os mesmos telejornais e todas as semanas os programas se distribuem de maneira fixa pelos dias certos na grade de programação das emissoras - introduz uma temporalidade particular marcada, inexoravelmente, por novos começos. A matriz cultural do tempo organizado pela televisão é dependente da lógica da repetição e do fragmento. Instaura-se, portanto, um tempo ritual que é, também, rotina.

A televisão tem como fundamento um tempo repetitivo, que produz a sensação de duração. Sabemos que o telejornal durará 20 minutos, que a telenovela terá exatos 30 minutos e assim por diante. Além disso, cada um desses programas mesmo os não ficcionais - voltarão no dia seguinte, continuando a narrativa da véspera e construindo a idéia de continuidade. Para o público, portanto, cada um daqueles textos replica e reenvia aos anteriores, pertencentes ao mesmo gênero televisual. Há, pois, múltiplos tempos incluídos na grade de programação: o tempo 
do telejornal, o tempo da telenovela, o tempo dos programas humorísticos e assim por diante. Os tempos são arquitetados também pelas tipologias narrativas que aparecem sempre nos mesmos dias da semana e nos mesmos horários.

Finalmente há que se considerar o que é conceituado por Jesus MartinBarbero (1998) como competência cultural. Ou seja, existe um lugar próprio para a televisão e é deste lugar que fala com o público e, sobretudo, produz a especificidade de suas narrativas. Como pertencente à cultura de massa, a televisão vai se adequar às regras estéticas de seu gênero e atuar culturalmente. O público irá reconhecer nos múltiplos textos produzidos gêneros plurais, ativando suas competências culturais a partir da produção narrativa. É por esta razão que Barbero enfatiza o fato de os gêneros constituírem uma forma de mediação fundamental entre os sistemas produtivos e os de consumo, acionando modos de ler e usos diferenciados.

Uma narrativa que coloca em primeiro plano a imagem. Uma narrativa que acopla imagem e som, incluindo o audível e o inaudível, numa mesma formatação discursiva.

A narrativa da TV destaca a imagem. Mais do que o mundo das coisas contadas está em cena o mundo das coisas vistas. A luz que permite a construção imagética reproduz pessoas em presença, lugares conhecidos ou desconhecidos, caleidoscópio de imagens múltiplas.

Apesar de aparentemente ter como prevalência a imagem, coloca em cena, também como já enfatizamos, particularidades do diálogo e da forma de comunicação oral, sendo, como particulariza Arlindo Machado (2003), um meio bem pouco visual. Aceitando, como tão lucidamente faz Machado, que no conceito televisão estão incluídos não apenas conteúdos figurativos, narrativos e temáticos, como também o modo de manejar os elementos dos códigos visuais e que há "esferas de intenção mais ou menos bem definidas, no interior dos quais os enunciados podem ser codificados de forma relativamente estável”, é preciso considerar também que esses "campos de acontecimentos audiovisuais" contêm modos de narrar de outros meios (cinema, literatura, teatro, jornalismo, etc.). Mas cada um desses modos sofre na televisão modificações, construindo uma narrativa de infinitas possibilidades 
(Idem, p. 70-71). Na televisão, o "mundo do autor" se transforma no "mundo do leitor" (RICOUER, 1996).

A partir de um primeiro diálogo com o público, que parece sentir o que vê na tela, a memória que este particulariza sobre as emissões vem do mundo das sensações. Se a narrativa pressupõe uma compreensão do mundo para se exprimir posteriormente sob a forma de explicação, a transmissão de cenas desse mundo que se particulariza pelo olho do telespectador e se completa por um outro olho, que vendo a cena original a retransmite para todos (essa é a impressão que se tem), a televisão mostra aspectos desse mundo sempre sob a forma de um presente aprisionado. $\mathrm{O}$ mundo expresso na imagem narrativa da TV é sempre um mundo pretensamente compreendido.

O que chamamos de narrativa televisual é, pois, o resultado de um processo de entrelaçamentos de múltiplas linguagens e gêneros midiáticos - considerando a produção de discursos hegemônicos e contra-hegemônicos ou se quisermos estratégias e táticas, no sentido de Certeau (2000), que remetem ao exercício das artes de fazer produzido pelo público - tendo, como pano de fundo, duas outras questões fundamentais: a imagem e o imaginário. Nessa linguagem observa-se o amálgama de práticas culturais que se revelam em modos de contar histórias, ora dependente da convenção de veracidade, ora dependente da convenção de ficcionalidade.

Essas dependências, entretanto, não invalidam o embaralhamento de fronteiras que remete à produção dos discursos cotidianos, onde também se conta histórias em que o informacional, por exemplo, pode ser revelado pelo exagero das formas ficcionais. Esses regimes são dependentes de estratégias narrativas que remetem a historicidades precisas. A televisão organiza o imaginário, em redes híbridas, onde se entrelaçam o real e o fantástico, a vida e a imaginação.

Mas tem também a capacidade de representar o social, de construir a atualidade e de mostrar e acompanhar as mudanças que ocorrem no mundo. É nesse sentido que se transfigura em testemunha e procura mostrar a complexidade da sociedade na tela (BARBERO, 2001, p. 73). 
A entronização do papel de testemunha afeta, muitas vezes, a temática e a forma como constrói determinadas narrativas. A novela Páginas da Vida (Rede Globo, 2006) talvez seja um bom exemplo do efeito testemunho utilizado pela televisão. Na telenovela, o ficcional apresentado como um turbilhão de imagens e de situações cotidianas familiares ao público transcorre durante todo o tempo da emissão. Ao final, sob a forma de testemunho, um rosto desconhecido relata uma experiência de vida. A vida em capítulos da telenovela se transforma em vida real na fala do entrevistado do dia. O capítulo se encerra sempre com esta presunção de mundo real. E no dia seguinte, Páginas da Vida são encenadas novamente do ponto de vista ficcional 4 .

Dependente da lógica da fragmentação e do fluxo, a narrativa da TV apresenta outras as características necessárias à construção dessa ambiência: há a prevalência do ritmo sobre outros elementos narrativos, o domínio dos efeitos tecnológicos sobre a história, a diminuição da complexidade dos personagens e a simplificação das tramas. Figura no discurso da televisão, como enfatiza Barbero (2001, p. 149), a longa duração do relato primordial, o que leva a representação de rituais de ação e a codificação da experiência, impondo um universo regulado pela bipolaridade entre vilões e heróis, com a gramática fragmentada do meio.

Por outro lado, a ligação da televisão com as estratégias da oralidade e com a cultura oral, permite em muitas emissões (sobretudo nas telenovelas) explorar o universo das lendas dos heróis e das temáticas mirabolantes do universo fantástico, a fantasia do improvável e do mistério. Narrativas imemoriais que migraram de um imaginário fantástico e fantasioso, materializados sob a forma de impressos, para a forma imagem. Predomina na gramática da TV o ato de contar, estabelecendo-se a continuidade temporal - todos os dias se contam várias histórias - pelo ato narrativo. E o desconhecido se torna conhecido. O que move a gramática da televisão é o drama do reconhecimento.

\footnotetext{
4 O efeito testemunho parece cada vez mais fazer parte da lógica narrativa da televisão. Também no humor, o testemunho pode validar todo o desencadeamento da produção narrativa. Este é o caso, por exemplo, de Retrato Falado, programa humorístico estrelado por Denise Fraga na TV Globo desde 2000. Sobre o efeito testemunho e Retrato Falado, cf. CAMINHA (2007).
} 
Enfim, a lógica da vida em capítulos - um dia após o outro - como a própria existência é remontada pela televisão, que produz uma estratégia fundamental de ilusão da realidade, ao mesmo tempo em que se torna presença obrigatória no cotidiano. Tal como a vida que ocorre dia após dia, também a televisão constrói sua narratividade dia após dia, acompanhando em progressão a vida e, por isso mesmo, sendo parte constitutiva da existência.

Outra característica marcante dessas narrativas é a presunção de que se dirigem a um auditório universal. O sentido implica a inclusão de um vasto universo definido como público. E é fundamental para essa inclusão infinita a construção da lógica narrativa pressupondo linearidade. Ser inteligível para um vasto auditório significa comunicar a experiência. E comunicar a experiência é ver em conjunto, numa seqüencialidade natural: cada coisa tem o seu lugar e cada coisa acontece uma depois da outra.

Assim, a temporalidade das narrativas instaura uma seqüencialidade infinita, ainda que sem a delimitação clara de fronteiras entre passado, presente e futuro. A competência de se aproximar do universo cultural do público significa também construir uma apropriação temporal que se aproxime da lógica da experiência desse vasto auditório. O tempo vulgar - comum e peculiar à existência -, é o que figura na tela da TV: o presente é infinito, o futuro é alvo de antecipações e projetos e o passado, como momento de recordações intermináveis, possui uma correlação singular com o presente. Ele só existe para pressupor a existência do agora.

O tempo da televisão reinstala também a percepção mais fundamental do tempo vulgar: o apagamento da idéia de finitude. Através das narrativas ficcionais morre-se e renasce-se no momento seguinte. E mesmo as cerimônias midiáticas que informam sob uma morte incomum constroem a significação do morto como eterno: sua elevação à categoria de mito transforma sua face no rosto de personagem da história. Através da história, permanecerá vivo na memória das multidões.

Um tempo infinito, já que pressupõe que nossa duração é apenas um fragmento, de onde se apaga a idéia de finitude originária, governa as narrativas da televisão. Uma espécie de tempo imortal, atualizando permanentemente a idéia de 
que a duração de nossa vida é apenas fragmento desse tempo. O tempo também parece "fugir" nas narrativas da TV e no seu lugar instala-se o fluxo neutro de 'agoras' pontuais. Um depois do outro, uma coisa depois da outra, como em todo pressuposto comunicativo de qualquer narrativa.

O tempo vulgar, para Ricoeur pode ser caracterizado como uma seqüência de 'agoras' pontuais cujos intervalos são medidos por nossos relógios. "Como a agulha em seu percurso, continua ele, o tempo corre de um 'agora' a outro. O tempo assim definido merece ser chamado de 'tempo do agora" (1996, p. 141) 5.

Outra característica do tempo vulgar é a universalidade, ou seja, o seu caráter pretensamente irredutível. O tempo é tido como público, por ser declarado universal. Só se define como sistema de datas porque a datação se inicia num 'agora' qualquer: define-se como conjunto de intervalos e o tempo universal é a seqüência de 'agoras' pontuais (Idem, p. 42).

A lógica narrativa da programação da TV é construída por essas seqüências de "agoras". Após um programa um novo agora introduz um outro. E, assim, numa sequiência interminável que se repete no outro dia. As emissões cerimoniais, nesse jogo, introduzem a idéia de instante. Não é um novo agora que marca a emissão, mas um corte abrupto interrompendo de maneira arbitrária o tempo, o agora. Mas ambos, instante e agora, são tempos narrados.

Cada uma das emissões diz respeito a ações, cujos projetos ou resultados, podem ser visualizados pelos telespectadores como semelhantes às suas próprias ações. Mas a pretensão do telespectador é que cada história seja única e singular, algo que jamais foi mostrado, cenas que jamais foram vistas.

Tudo isso dentro de convenções narrativas. Nas emissões governadas pela lógica informativa espera-se a inclusão da 'verdade', ou seja, o que está definido no limite do verdadeiro. Nas emissões governadas pela ficcionalidade, o verossímil entra em cena. "Toda história contada refere-se a algum sucesso ou a algum fracasso de

\footnotetext{
5 Ricoeur critica a idéia englobante sob o nome de tempo vulgar. Para ele "a própria expressão tempo vulgar parece ridícula diante da amplitude dos problemas propostos à ciência pela orientação, a continuidade, mensurabilidade do tempo". A luz desses trabalhos, de uma tecnicidade cada vez maior, se pergunta se seria possível opor um conceito científico único de tempo às análises fenomenológicas, também múltiplas, recebidas de Santo Agostinho, de Husserl e de Heidegger (Idem, p. 145).
} 
homens que vivem e trabalham juntos, em sociedade ou nações, com pretensão ao verdadeiro e ao verossímil" (RICOEUR, 1994, p. 217). O que confere unidade orgânica a cada uma delas é o ato de seguir a narrativa. O entendimento do público está diretamente relacionado a sua competência de seguir a história, da mesma forma que o jornalista segue a história ao contar cada uma delas como se fosse una e singular.

Mas as histórias só merecem ser narradas e seguidas se o tema se referir a interesses que dizem respeito a qualidades (ou a não qualidades, por contraponto) dos seres humanos. Há, portanto, em toda narrativa um nexo fundamental com os sentimentos.

Mas nos jogos de pré-compreensão do mundo, figuração do mesmo mundo (produção da notícia) e re-figuração (apropriação produzida), tão bem e lucidamente interpretado por Ricoeur (1994, 1995 e 1996), o público produz pluralidade de sentidos, que incluem críticas explícitas às interpretações produzidas pelos jornalistas. Nos jogos com a arte de narrar, o jornalismo conta histórias, mas o público re-conta histórias. Essas narrativas, devem ter mais do que o nexo com uma pretensa verdade: devem fazer parte do mundo do verossímil, algumas vezes, e outras tantas espelhar os sentimentos que envolvem necessariamente aquelas descrições. Quando não cumprem esse compromisso, os meios de comunicação contam histórias sob uma perspectiva completamente diversa do que espera o público. 


\section{Referências Bibliográficas:}

BARBERO, Jesus-Martin e REY, German. Os exercícios do ver. Hegemonia audiovisual e ficção televisiva. São Paulo: Editora SENAC, 2001.

BARBERO, Jésus-Martin. Dos meios às mediações. Rio de Janeiro: UFRJ, 1998.

BARTHES, Roland. $S / Z$. Paris: Seuil, 1970.

CAMINHA, Marina. Uma fábula cômica do cotidiano: As marcas do documentário e do melodrama na construção do riso em Retrato Falado. Dissertação de Mestrado. Niterói: PPGCOM - UFF, 2007.

CHARTIER, Roger. Les usages de l'imprimé (XV - XIX siècles). Paris: Fayard, 1987.

CHARTIER, Roger. Pratiques de la lecture. Paris: Payot, 1993.

DE CERTEAU, Michel. A invenção do cotidiano. As artes de fazer. Petrópolis: Vozes, 2000.

GENETTE, Gérard. Figures III. Paris: Seuil, 1972

GENETTE, Gérard. Nouveau discours du récit. Paris : Seuil, 1983.

KERCKHOV, Derrick de. A pele da cultura. Lisboa: Relógio D’Água Editores, 1997.

MACHADO, Arlindo. A televisão levada a sério. São Paulo: SENAC, 2003.

RICOEUR, Paul Tempo e Narrativa. Vol. I. Campinas: Papirus, 1994.

RICOEUR, Paul Tempo e Narrativa. Vol. II. Campinas: Papirus, 1995.

RICOEUR, Paul Tempo e Narrativa. Vol. III. Campinas : Papirus, 1996

TODOROV, T. As estruturas narrativas. Rio de Janeiro: Perspectiva, 1979.

WILLIAMS, R. Marxismo e Literatura. Rio de Janeiro: Zahar Editores, 1979

WILLIAMS, Raymond. Television, technology and cultural form. Londres, Routledge, 1990.

ZUMTHOR, Paul. A letra e a voz. São Paulo: Companhia das Letras, 1993. 